\title{
Mandatory SARS-CoV-2 Vaccinations in K-12 Schools, Colleges/ Universities, and Businesses
}

\author{
Lawrence O. Gostin \\ Georgetown University - Law Center - O'Neill Institute for National and Global Health Law, \\ gostin@law.georgetown.edu \\ Jana Shaw \\ Division of Infectious Diseases, Department of Pediatrics, SUNY Upstate Medical University \\ Daniel A. Salmon \\ Institute for Vaccine Safety, Johns Hopkins University - Bloomberg School of Public Health, \\ dsalmon1@jhu.edu
}

This paper can be downloaded free of charge from:

https://scholarship.law.georgetown.edu/facpub/2388

https://ssrn.com/abstract=3863585

The Journal of the American Medical Association, published online June 7, 2021, at E1-E2.

This open-access article is brought to you by the Georgetown Law Library. Posted with permission of the author. Follow this and additional works at: https://scholarship.law.georgetown.edu/facpub

Part of the Food and Drug Law Commons, Health Law and Policy Commons, Human Rights Law Commons, and the Law and Politics Commons 


\section{Mandatory SARS-CoV-2 Vaccinations in K-12 Schools, Colleges/Universities, and Businesses}

Lawrence O. Gostin, JD O'Neill Institute for National and Global Health Law, World Health Organization Collaborating Center on National and Global Health Law,

Georgetown Law, Washington, DC.

Jana Shaw, MD, MPH Upstate Golisano Children's Hospital Epidemiologist, Pediatric Infectious Diseases, SUNY Upstate Medical University, Syracuse, New York.

Daniel A. Salmon, PhD, MPH

Institute for Vaccine Safety, Department of International Health, Department of Health, Behavior and Society, Johns Hopkins Bloomberg School of Public Health, Baltimore, Maryland.

$\boldsymbol{\Psi}$ Viewpoint

\section{Corresponding}

Author: Lawrence O. Gostin, JD, O'Neill Institute for National and Global Health Law, Georgetown Law, 600 New Jersey Ave NW, McDonough 568, Washington, DC 2000 (gostin@georgetown. edu).
The Centers for Disease Control and Prevention (CDC) recently issued guidance that fully vaccinated individuals can safely remove masks and end social distancing in most indoor settings. ${ }^{1}$ Educational facilities and businesses are faced with whether and how to differentiate between vaccinated and unvaccinated individuals, including requiring proof of vaccination. Mandatory vaccination has historically served as a tool to reach and sustain high immunization coverage and to prevent transmission in K-12 schools, colleges/ universities, and health care facilities. Vaccine mandates could extend to workers and customers in businesses to ensuresafer environments. This Viewpoint examines the epidemiologic, publichealth, and legal considerations for mandatory SARS-CoV-2 vaccinations in each setting.

\section{K-12 Schools}

States have police powers to safeguard the public's health, which includes mandatory vaccination. Every state currently requires childhood vaccinations as a condition of school entry, often aligned with the CDC's Advisory Committee on Immunization Practices recommendations, although there is wide variability among states. All states grant medical exemptions, 44 states and

\section{Mandates and proof of vaccination are likely to enhance coverage and do so equitably, provided that doses are available to all without barriers, irrespective of socioeconomic or other status.}

the District of Columbia grant religious exemptions, 15 states allow philosophical exemptions, and 6 states grant only medical exemptions. ${ }^{2}$

Although SARS-CoV-2 infections among children are typically asymptomatic or mild, severe symptoms can lead to hospitalization. Rare cases of multisystem inflammatory syndrome in children also occur. As of May 27, 2021, the American Academy of Pediatrics and the Children's Hospital Association jointly reported 3977870 cumulative pediatric COVID-19 cases, 16525 cumulative hospitalizations, and 322 cumulative deaths. ${ }^{3}$ These data represent underreporting of the true extent of SARS-CoV-2 infection in children because many states did not contribute to the joint report and the number of children infected but not tested and confirmed infected is unavailable. New pediatric infections are increasing, with children currently comprising $24 \%$ of new SARS-CoV-2 cases for the week ending May 27, 2021.

The Food and Drug Administration (FDA) has granted Emergency Use Authorization (EUA) for 3SARS-
CoV-2 vaccines. The FDA recently extended its EUA for the BNT162b2 (Pfizer-BioNTech) vaccine to 12- to 15year-olds. The American Academy of Pediatrics also recommends SARS-CoV-2 vaccinations for all eligible youths. The FDA could decrease the age of eligibility to 6 months by January 2022 and is expected to issue a full Biologics License Application for the BNT162b2 vaccine before the 2021-2022 school year.

Vaccination of children is essential to gain high vaccination coverage and mitigate transmission. BNT162b2 vaccine was reported to be $100 \%$ effective in protecting adolescents aged 12 to 15 years against symptomatic disease. Mounting evidence also shows that all authorized COVID-19 vaccines reduce SARS-CoV-2 transmission. ${ }^{4}$ Children spend substantial time at school, day care, and after-school activities. Vaccines therefore will provide important direct and indirect benefits.

Despiteclear benefits of childhood vaccination, school mandates do not yet meet public health criteria such as postmarketing surveillanceestablishing longer-term safety and strong support from health care professionals and the public. ${ }^{5}$ SARS-CoV-2 vaccine mandates in children would bepremature. Using incentives instead of mandates would avoid public backlash that could undermine the SARS-CoV-2 vaccine rollout.

\section{Postsecondary Education}

Colleges and universities often require on-campus students to be vaccinated against viral infections such as measles, mumps, rubella, and meningococcal disease, especially those living in crowded settings, including residence halls and other congregate settings (eg, fraternity and sorority houses). Postsecondary educational institutions that remained open during the 2020-2021 school year experienced SARS-CoV-2 spread higher than the national average, with more than 660000 reported probable and confirmed cases and 100 deaths. ${ }^{6}$

Consequently, many colleges and universities have announced plans to mandate vaccinations for students, and others have included faculty and staff. These institutions have not faced successful legal challenges to their current vaccine mandates, and it is likely the courts would support mandatory SARS-CoV-2 vaccines. The Equal Employment Opportunity Commission (EEOC) has issued guidance saying that vaccine mandates would be lawful, even under an EUA. Institutions, however, must grant medical and religious exemptions.

International students may not have access to FDAauthorized vaccines, so determining which products to include in the mandate will be key. The World Health Organization (WHO) has given emergency use listing for all 
FDA-authorized vaccines, as well as for the Sinopharm, Sinovac, and Oxford University/AstraZeneca vaccines. For international students, US universities could potentially accept all vaccines that receive WHO emergency use listing. Educational institutions will also have to decide the safety protocols for individuals with medical or religious exemptions, including remote learning or a rigorous protocol of testing, symptom monitoring, and mask usage.

\section{Businesses}

Employees with close and prolonged contact with coworkers, customers, or both have increased risk of acquiring and transmitting infection. Superspreader events have been linked to bars, restaurants, weddings, churches, athletics, and food processing plants. A large percentage of the population is at risk of SARS-CoV-2: as of June 2, 2021, approximately $41 \%$ of the population had been fully vaccinated ${ }^{7}$; children younger than 12 years are not eligible, and others are immunosuppressed and may remain at risk for severe infection and transmission despite vaccination.

The Occupational Safety and Health Administration, as well as tort law, requires employers to provide a safe and healthy workplace. The administration recommends no-cost SARS-CoV-2 vaccinations for all eligible employees. EEOC guidance specifically permits businesses to require SARS-CoV-2 vaccination as a condition of employment, provided employers offer medical and religious exemptions. Asking for immunization status does not violate the right to privacy, provided the information is secure and does not require additional medical information. HIPAA (Health Insurance Portability and Accountability Act) applies only to health information kept by "covered entities," primarily those providing health care services.

Despite EEOC guidance, businesses must comply with the law in the states in which they operate. At least 11 states have enacted laws (4) or issued executive orders (7) restricting SARS-CoV-2 mandates or proof of vaccination. Statutes or executive orders vary considerably in scope, with some limiting employer verification of vaccine status and others applying only to state and local agencies.

Unless proscribed by state law, private companies have wide discretion in conducting their business operations, provided they do not discriminate according to race, sex, disability, or other legally protected status. Businesses often set conditions on offering goods and services, such as requiring "shoes, shirts, and masking." CDC guidance distinguishes between vaccinated and unvaccinated individu- als, advising the latter to continue to mask and distance. Yet CDC leaves the private sector to implement its recommendations. The airline industry is testing mobile applications to verify immunization status of crew and passengers. New York is piloting its Excelsior Pass, allowing patrons to upload proof of vaccination or negative SARS-CoV-2 test results through written documentation or a digital application. Companies such as Walmart are providing economic incentives for vaccine status, and some include electronic verification. President Biden also called on employers to provide paid time off for vaccination and time needed to recover from vaccinerelated adverse effects.

\section{Mandating or Incentivizing SARS-CoV-2 Vaccinations}

Mandates and proof of vaccination are likely to enhance coverage and do so equitably, provided that doses are available to all without barriers, irrespective of socioeconomic or other status. High vaccination coverage is the single most effective way for a safer return to normal activities. Mandates are most effective if high vaccination coverage cannot be achieved through other methods, reducing the risk that mandates could provoke a backlash.

Positive incentives could boost vaccination rates, including cash payments or time off from work, or reimbursement of childcare expenses associated with accessing a vaccine. Incentives at colleges and universities could include enforcement of recent CDC masking and distancing guidance, allowing vaccinated students to forgo mask wearing and attend social functions without distancing constraints. Furthermore, requiring unvaccinated individuals to undergo rigorous safety protocols (eg, testing, symptom monitoring, masking), or working or learning remotely, could encourage individuals who are vaccine hesitant. Educational institutions or businesses could also routinely offer SARS-CoV-2 vaccines at no cost, requiring individuals to affirmatively opt out, perhaps with an appropriate process, such as a brief vaccine literacy course, a written explanation for refusal, or both. Routine offering of vaccines with a process for opting out has been shown to boost vaccination coverage.

The goal of SARS-COV-2 vaccination programs is to end the pandemic and maintain control of COVID-19 disease. Achieving this goal requires very high and homogeneous vaccine coverage to establish and maintain herd immunity. Vaccine mandates are a potential tool to achieve high vaccine coverage and may be valuable in addition to other public health interventions.

\section{ARTICLE INFORMATION}

Published Online: June 7, 2021 doi:10.1001/jama.2021.9342

Conflict of Interest Disclosures: Mr Gostin reported being the director of the World Health Organization Collaborating Center on National and Global Health Law. Dr Shaw reported serving on a Pfizer speakers' bureau for meningococcal vaccine. Dr Salmon reported receiving research grants from Merck and Walgreens, and is a paid member of an advisory board for Janssen.

\section{REFERENCES}

1. Centers for Disease Control and Prevention. Interim public health recommendations for fully vaccinated people. Updated May 13, 2021. Accessed May 20, 2021. https://www.cdc.gov/ coronavirus/2019-ncov/vaccines/fully-vaccinatedguidance.html

2. National Conference of State Legislatures. States with religious and philosophical exemptions from school immunization requirements. Accessed May 20, 2021. https://www.ncsl.org/research/health/ school-immunization-exemption-state-laws.aspx

3. American Academy of Pediatrics. Children and COVID-19: state-level data report. Updated May 17, 2021. Accessed May 20, 2021. https://services. aap.org/en/pages/2019-novel-coronavirus-covid19-infections/children-and-covid-19-state-leveldata-report/

4. Centers for Disease Control and Prevention. Science brief: COVID-19 vaccines and vaccination. Updated May 27, 2021. Accessed May 20, 2021. https://www.cdc.gov/coronavirus/2019-ncov/ science/science-briefs/fully-vaccinated-people. html

5. Opel DJ, Diekema DS, Ross LF. Should we mandate a COVID-19 vaccine for children? JAMA Pediatr. 2021;175(2):125-126. doi:10.1001/ jamapediatrics.2020.3019

6. New York Times. Tracking coronavirus cases at US colleges and universities. Updated April 30, 2021. Accessed May 20, 2021. https://www. nytimes.com/interactive/2021/us/college-covidtracker.html

7. Centers for Disease Control and Prevention. COVID data tracker: COVID-19 vaccinations in the United States. Accessed May 20, 2021. https:// covid.cdc.gov/covid-data-tracker/\#vaccinations 